\title{
SUBALTERNIDAD Y CONTRAHEGEMONÍA EN LA NARRATIVA TESTIMONIAL KICHWA DE LA SIERRA NORTE DEL ECUADOR
}

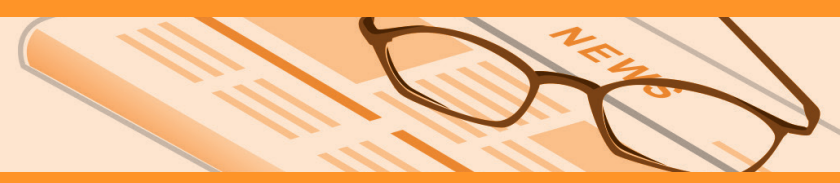

Autor:

Jorge Gómez Rendón ${ }^{1}$

${ }^{1}$ Universiteit van Amsterdam

Amsterdam Center for Language and Communication

http://home.medewerker.uva.nl/j.a.gomezrendon/

Pontificia Universidad Católica del Ecuador

Facultad de Comunicación, Lingüística y Literatura

www.puce.edu.ec

Email: j.a.gomezrendon@uva.nl / Teléf.: (593) 09980480421

Quito - Ecuador / Septiembre 2013

Recibido: 2013-05-30

Aprobado: 2013-08-10

Publicado: 2013-12-18

REVISTA DE INVESTIGACIÓN CIENTÍIFICA 


\section{Resumen}

El testimonio es un género de la praxis discursiva de sujetos subalternos que ejercen a través de él su derecho a la palabra y la representación, paralelamente a los discursos dominantes. El testimonio conforma sus elementos a través de estrategias lingüísticas propias. Un estudio previo de los elementos narrativos del testimonio con herramientas del análisis tradicional dejó fuera los mecanismos de auto-representación del sujeto narrativo y de representación de los actores sociales en el discurso. La presente investigación tiene como objetivo estudiar las identidades tal como se construyen y proyectan en el testimonio, a partir de nuevas herramientas proporcionadas por el Análisis Crítico del Discurso. Se estudia así el uso estratégico de determinados elementos lingüísticos en un corpus representativo de testimonios sobre la vida en la hacienda, los cuales se recogieron en varias comunidades de la parroquia San Pablo del Lago, en la Sierra norte del Ecuador. Los elementos lingüísticos cuyo uso se analiza aquí son cuatro: los pronombres, como representación verbal del sujeto por excelencia; el discurso reportado directo, como forma eminente de lo dialógico y lo intertextual; las comparaciones figuradas, como reflejo de la cosmovisión del hablante; y las evaluaciones, como elementos estéticos del discurso.

Palabras clave: testimonio, subalternidad, contrahegemonía, análisis crítico del discurso, pronombres, discurso directo, comparaciones, evaluaciones.

\section{Abstract}

Testimonial narratives are a discursive gender of subaltern subjects who exert through it their right to express their own voices and represent themselves in parallel to dominant discourses. Testimonial narratives construct their elements on the basis of particular linguistic mechanisms. A previous study of the narrative elements of testimonio with tools of traditional analysis left aside the mechanism of selfrepresentation of the narrative subject and that of representation of social actors in discourse. This paper intends to study identities as they are constructed and projected onto testimonial narratives with the use of tools provided by Critical Discourse Analysis. It deals with the strategic use of specific linguistic elements in a representative corpus of testimonial narratives about the life in haciendas, which were collected in several communities in the parish of San Pablo del Lago in the northern Ecuadorian Highlands. Four are the linguistic elements under analysis: pronouns as the privileged linguistic representation of subjects; direct speech acts as conspicuous forms of dialogicity and intertextuality; figurative comparisons as a mirror of speakers' worldviews; and evaluations as aesthetic elements of discourse.

Key words: subalternity, counter-hegemony, critical discourse analysis, pronouns, direct speech, comparison, assessment. 


\section{Introducción}

Un primer análisis de la narrativa testimonial en las antiguas comunidades de hacienda de la parroquia San Pablo del Lago' utilizó herramientas del análisis narrativo tradicional, como la identificación de la estructura episódica del texto y el trazado de relaciones entre personajes a través de intercambios de objetos que recrean relaciones de poder en el espacio-tiempo de la fiesta indígena. Partiendo del supuesto que el testimoniante construye sus propios objetos de conocimiento a través del discurso narrativo, se propusieron cinco categorías de análisis que incluían escenarios, actores, intercambios, itinerarios y objetos. Se encontró que los intercambios se articulaban a lo largo de itinerarios que describían flujos de objetos y desplazamiento de actores entre distintos escenarios de poder, y que la dirección y (a)simetría de dichos itinerarios determinaba la relación de poder predominante y el escenario principal. Sin embargo, en el transcurso del análisis, se fue haciendo evidente que las entidades que correspondían a las categorías de análisis arriba mencionadas no equivalían a las entidades del análisis social y la descripción histórica. El desfase más claro entre dos entidades de una misma categoría era aquél entre el escenario de la 'hacienda' en los testimonios y el espacio productivo del mismo nombre en los estudios sociales. Otro desfase - aún de mayor relevancia para el análisis - involucraba a la entidades agrupadas bajo la categoría de 'actores sociales'. En este caso se encontró que el sujeto enunciador o testimoniante no se auto-representaba siempre como actor individual y su identidad se constituía a menudo en referencia a un colectivo social ${ }^{2}$. El primer análisis, sin embargo, no llegó a deconstruir la representación de los sujetos narrativos, al asumirlos como entidades previamente constituidas que encajaban perfectamente en constructos teóricos tales como ‘hacendado', ‘huasipunguero' o ‘yanapero'.

'Jorge Gómez Rendón (2001). La voz del subalterno a través del testimonio: una fuente para el estudio de las relaciones de poder en las fiestas de la parroquia San Pablo del Lago. Tesis de Maestría. Programa de Maestría de Estudios de la Cultura. Universidad Andina Simón Bolívar. Quito.

${ }^{2}$ Este proceso metonímico en la auto-representación del sujeto narrativo se considera propio del testimonio y se refleja en su naturaleza polifónica o dialógica (Beverly 1987: 56).
Un sujeto enunciador que no coincide con el sujeto narrativo y unos escenarios narrativos que no reflejan los espacios sociales conocidos sugieren un desajuste en otros órdenes del discurso. Existiría entonces una falta de correspondencia entre las identidades del discurso testimonial y las entidades de la teoría social, lo cual apoyaría decisivamente la afirmación de que el testimonio es una práctica des-subalternizante.

Con estos antecedentes, se planteó una nueva lectura de los testimonios que pudiera desentrañar los procesos de construcción de las (id)entidades en el discurso y determinar su relación con los actores del análisis socio-histórico. Los resultados de este ejercicio no sólo refinarían el análisis del testimonio sino que ofrecerían una nueva perspectiva sobre su carácter polifónico y dialógico. Para ello era necesario disponer de herramientas que pusieran al descubierto el uso del lenguaje en la construcción discursiva de los objetos; herramientas que fueran lo bastante precisas para desentrañar la maraña de los textos pero que tuvieran al mismo tiempo un fuerte respaldo teórico que no comprometa su valor operativo. En otras palabras, eran necesarias herramientas que vincularan el análisis textual a la praxis social, y viceversa. Como veremos más adelante, estas herramientas no son las del análisis literario bakhtiniano ni tampoco las del análisis discursivo foucaultiano, aun cuando ambos ofrecen un valioso encuadre teórico para el ejercicio analítico. Al contrario, creemos haberlas encontrado y lo demostraremos a lo largo de este artículo - en la novel disciplina del Análisis Crítico del Discurso (en adelante ACD) inaugurada por Fairclough (1995) y van Dijk (1993).

\section{Métodos y Materiales}

El corpus del primer análisis consistió en una docena de narraciones testimoniales recogidas entre individuos de diferentes edades, géneros y comunidades de origen en la parroquia San Pablo del Lago, en la Provincia de Imbabura. Su temática giraba en torno a las fiestas celebradas en la hacienda (Uyanzas, Ramas de Gallo) y la cabecera parroquial (Patrón de San Pablo) entre los años cuarenta y 
sesenta del siglo pasado. De este corpus escogimos para los propósitos de esta investigación tres testimonios que pertenecen a dos hombres y una mujer originarios de tres comunidades distintas: El Topo, Casco Valenzuela y Cochaloma. Mientras la comunidad de El Topo perteneció al complejo hacendario de Zuleta, las dos últimas se ubicaron fuera de él. En ambos casos, las relaciones de las comunidades con la antigua hacienda fueron permanentes hasta la disolución de ésta a principios de los años ochenta. Dichas relaciones se manifestaban en dos formas de trabajo precario: el huasipungo en el caso de El Topo y la ‘yanapa' o trabajo estacional en el caso de Cochaloma y Casco. Concordantemente, la ocupación de cada narrador fue diferente según su comunidad: Amalia (68) fue empleada doméstica de la hacienda, Bernardo (66) huasipunguero, y Segundo (78) yanapero. El caso de este último es interesante porque, a diferencia de Bernardo y Amalia, su trabajo temporal para la hacienda se complementaba con trabajos estacionales en otros latifundios de la zona. Por todo lo anterior, creemos que las tres narrativas seleccionadas representan suficientemente las relaciones sociales de las comunidades de San Pablo con las haciendas de la zona. En conjunto, los testimonios seleccionados comprenden un total de tres horas y media de grabación, con un total aproximado de 13.000 palabras. Aunque fueron recogidos principalmente en kichwa, algunos pasajes están en castellano. Lejos de alterar los resultados, dichos pasajes los corroboraron, al aplicarse las mismas herramientas tanto a los textos kichwas como a los castellanos. Tampoco hubo uniformidad en el tipo de kichwa utilizado por los testimoniantes: el habla de Bernardo y Amalia es visiblemente más conservadora - y por lo tanto menos castellanizada - que la de Segundo, como era de esperar por el intenso contacto de éste con la sociedad hispanohablante a lo largo de su larga historia de migraciones laborales. De una u otra forma, se nota en los testimonios una importante mezcla con el castellano, bien en forma de préstamos o de cambios de código. Como hemos demostrado en otro lugar (Gómez Rendón 2008: 127s), esta mezcla es utilizada estratégicamente por el hablante para posicionarse socialmente en un evento comunicativo que involucra el uso de la lengua indígena.
Los testimonios seleccionados, previamente transcritos, fueron analizados según las categorías que se explican en la siguiente sección. Los resultados del análisis se recogieron y ordenaron en una base de datos, a partir de la cual se produjeron estadísticas para las categorías de análisis y se estudió luego las tendencias encontradas con base en los contextos de enunciación de cada testimonio. De esta manera, los resultados que se presentan aquí están apoyados en datos empíricos de primera mano, debidamente sistematizados y trabajados cuantitativa y cualitativamente. Pese a estas ventajas, es preciso reconocer los modestos alcances de la presente investigación, debido a los siguientes factores: a) el pequeño número de testimonios analizados; b) la matriz temporal (1940-1960) y espacial (comunidades indígenas de El Topo, Casco Valenzuela y Cochaloma) de los mismos; y en especial 3) el ámbito específico de operativización de las categorías de análisis del ACD (las identidades). Estas consideraciones son precisas a la hora sopesar las conclusiones de la presente investigación, que han de servir como primer paso para la materialización de una investigación más amplia más en una disciplina que se abre campo en nuestro medio.

\section{Resultados}

\section{El análisis crítico del discurso}

Desde los escritos de Foucault sobre el discurso en los años sesenta y setenta (sobre todo Foucault 1969), el interés por el estudio del lenguaje creció significativamente en lo que se ha llamado el 'giro lingüístico’ en las ciencias sociales. De acuerdo con el filósofo francés (Foucault 1984), la palabra ‘discurso' engloba tres referentes distintos aunque relacionados: 1) el dominio general de todos los enunciados; 2) un grupo individualizado de enunciados; 3) una práctica regulada que da cuenta de un conjunto de enunciados. Esto significa que el término ‘discurso' se refiere no sólo a la esfera del texto - entendido éste en sentido amplio como concatenación coherente y orientada de enunciados - sino también a su proceso de conformación - la práctica socialmente regulada de emitir enunciados orientados a la producción y/o reproducción de un orden social. La preocupación de 
Subalternidad y contrahegemonía en la narrativa testimonial kichwa de la sierra norte del Ecuador

Foucault giró en torno al segundo de los significados de 'discurso', con lo cual demostró cómo su producción obedece a una serie de condiciones sociales e históricas que legitiman una configuración específica de relaciones de poder. Desde entonces las ciencias sociales abandonaron el estudio del discurso como conjunto sistemático de enunciados, por considerarlo secundario en relación con el estudio de la práctica discursiva. Esta postura ha sido revisada recientemente por cuanto, como señalan algunos,

"lo último que un analista serio debe hacer es adoptar sin crítica alguna ideas filosóficas o sociológicas acerca del lenguaje y el discurso que no están basadas en los avances de la lingüística contemporánea y el análisis del discurso" (van Dijk 2001: 364; mi traducción)

O bien simplemente porque,

"sin un análisis detallado, uno no puede en realidad demostrar que el lenguaje está haciendo el trabajo que teóricamente le asignamos" (Fairclough 2008: 204).

Casi contemporáneamente a la propuesta foucaultiana se produjo una reacción en la lingüística frente a las concepciones formalistas del lenguaje que querían entenderlo fuera de su contexto de producción. Una de las formas de esta reacción fue el análisis lingüístico del discurso, cuya meta era estudiar la concatenación de los enunciados y su interpretación en contexto. Aun así, pese a insistir la recuperación del contexto para cualquier interpretación global el lenguaje, la nueva disciplina trabajaba bajo una idea limitada de contexto, alejada de la praxis social y, sobre todo, de las condiciones socio-históricas de su producción. Se entiende así que para una de sus precursoras,

“el objetivo del análisis del discurso sea explicar cómo los hablantes interpretan, casi sin error, la deixis personal, temporal y espacial; recuperan objetos de mención anafórica; y producen respuestas que demuestran que conocen lo que ocurre en el diálogo, pese a los desbalances en el desarrollo ordenado del discurso" (Polanyi 2001: 265; mi traducción).
Este plan de investigación es necesariamente limitado por cuanto olvidan quienes lo practican que parte importante de esa interpretación "casi sin error" que hacen los hablantes, se basa en conocimientos compartidos sobre el mundo y en inferencias que provienen precisamente de su posición dentro en una configuración social de relaciones de poder. Por ejemplo, el uso de los llamados honoríficos o formas respetuosas de tratamiento no puede explicarse sólo con base en su estructura: el hablante debe saber bien cuándo, dónde y con quién usar un honorífico, y esto lo puede saber sólo si está inmerso en una configuración social de relaciones de poder³.

En otras palabras, un análisis del discurso que desatienda la estructura lingüística de los enunciados y la manera cómo se utiliza el lenguaje para producir y legitimar relaciones de poder, carece de justificación tanto como un análisis del discurso que haga caso omiso de estas relaciones a la hora de interpretar la estructura de los enunciados y el uso del lenguaje. Dicho esto, está claro que se requiere una postura intermedia para un abordaje sistemático y comprensivo del fenómeno del discurso. Este abordaje debe asumir una postura eminentemente crítica del uso del lenguaje, vinculándolo con la praxis social. Tal es el abordaje del Análisis Crítico del Discurso $(A C D)$, que en palabras de uno de sus principales precursores,

“es un tipo de investigación analítica del discurso que estudia principalmente la manera en que el abuso del poder, el dominio y la desigualdad son actuados, reproducidos y resistidos a través del texto y el habla en el contexto social y político" (Van Dijk 2001: 352).

Fairclough, por su parte, recalca que el ACD es "una forma de investigación social crítica [...] cuyo objetivo es comprender mejor cómo funcionan las sociedades, cómo producen efectos benéficos y nocivos, y cómo éstos últimos pueden ser mitigados y eliminados" (Fairclough 2008: 202-3).

${ }^{3} \mathrm{Al}$ respecto es muy iluminador el estudio pionero de Brown y Gilman (1960) sobre cómo los pronombres reflejan y sirven para crear poder o solidaridad según su uso. 
Esto implica varias cosas. En primer lugar - y en ello insisten quienes lo practican - el ACD no es un nivel de análisis más, como lo es la fonología, la morfología o la sintaxis - con lo cual se separa del análisis del discurso de vertiente estrictamente lingüística - sino una “exploración de cómo los ‘textos' funcionan a todos los niveles dentro de las prácticas socioculturales" (Fairclough 1995: vii). Requiere, por lo tanto, una actitud ecléctica con una metodología interdisciplinaria. He ahí que los teóricos del ACD recurran a conceptos tales como 'poder' (Foucault), ‘hegemonía' (Gramsci), ‘habitus' (Bourdieu) o 'polifonía’ (Bakhtin), provenientes de diversas corrientes del pensamiento social. Se explica igualmente el uso que el ACD da a estos conceptos, no fundiéndolos dentro de una teoría unitaria sino operativizándolos en un marco metodológico englobante. Esta postura, que se asemeja por lo demás a la pregonada por los Estudios Culturales, exige una revisión permanente del trabajo colaborativo y un ensayo continuo de nuevos enfoques analíticos. En segundo lugar - y en ello radica su perspectiva teórica y analítica en el campo de las ciencias sociales - el ACD se constituye en un ejercicio académico disidente, a través del cual el analista asume una posición explícita con respecto a la sociedad y lucha contra la desigualdad social, colaborando de diversas maneras con los grupos dominados o subalternos. La razón última para esta posición está en la convicción de que el vínculo entre discurso y sociedad siempre es mediado, es decir, el discurso por sí solo no tiene sentido sino en cuanto se actualiza en una estructura social determinada, creando y siendo creado por sus relaciones de poder. Con esta visión del ejercicio analítico, el ACD debe cumplir ciertos requisitos para la consecución de sus objetivos (van Dijk 2001: 353):

- Debe ofrecer una mejor perspectiva que la de otros análisis

- Debe enfocarse en problemas sociales más que en paradigmas y modas

- Debe ser interdisciplinario y empíricamente adecuado

- Debe explicar las estructuras del discurso según las propiedades de la interacción social y no conformarse con describirlas

- Debe enfocarse en la forma cómo las estructuras del discurso ejecutan, confirman, legitiman, reproducen o desafían relaciones de poder en la sociedad
El cumplimiento de estos requisitos implica la aceptación de ciertas premisas que guían el análisis crítico del discurso y sirven de marco de referencia para nuestro estudio. Fairclough y Wodak (1997: 271-80) resumen estas premisas de la siguiente manera:

Las relaciones de poder son discursivas

- El discurso constituye la sociedad y la cultura

- El discurso trabaja lo ideológico

- El discurso es histórico

- El vínculo entre texto y sociedad es mediado

- $\quad$ El discurso es una forma de acción social.

Toda vez que hemos trazado la visión, la misión y los objetivos del ACD, debemos operativizar el análisis crítico del discurso en la narrativa del testimonio. Para ello basamos el análisis en los postulados del ACD, contextualizándolos para el caso que nos ocupa y resaltando su relación con la situación etnolingüística de los testimoniantes y su comunidad.

\section{Operativización del ACD en el análisis de la narrativa testimonial}

El testimonio es, antes que nada, un ejercicio de la palabra, una práctica social mediada por el lenguaje, entendido éste no sólo por la capacidad humana de codificar símbolos a través de sonidos articulados, sino también por la forma específica que toma dicha capacidad de acuerdo con la comunidad de habla a la que pertenece el testimoniante. Es lógico, por lo mismo, que toda operativización de las herramientas del ACD empiece por una caracterización de la lengua y el contexto sociolingüístico en que se desarrolla el testimonio.

Los testimonios que analizamos en este trabajo fueron recogidos en la lengua materna del hablante, el kichwa, una lengua indígena tipológicamente distinta de la lengua oficial, el castellano. Siempre nos llamó la atención que los testimonios más conocidos en la literatura corriente hayan sido recogidos y publicados en castellano y no en la lengua nativa del hablante - que en la mayoría de casos no es el castellano. Creemos, por lo tanto, que el uso del kichwa en los testimonios otorga una impronta particular al mensaje que transmiten no sólo por el tipo de estructuras lingüísticas que utiliza 
Subalternidad y contrahegemonía en la narrativa testimonial kichwa de la sierra norte del Ecuador

el hablante - por ejemplo, el hecho de expresar a través de frases nominales complejas lo que en castellano se expresa mediante oraciones coordinadas - sino también por el contexto sociolingüístico del kichwa en nuestra sociedad. Sobre los tipos de estructuras relevantes al análisis discursivo del testimonio hablaremos más adelante. Por ahora concentremos la atención en el contexto comunicativo del testimonio.

Como en la absoluta mayoría de países hispanoamericanos, las lenguas indígenas - y entre ellas el kichwa - son en el Ecuador una lengua minorizada: primero, numéricamente, por el porcentaje relativo de individuos que la hablan con respecto a los hablantes del castellano; segundo, socialmente, por no ser la lengua oficial del estado nacional y hallarse limitada en cuanto a los espacios sociales de uso (Haboud 1998), pese a lo favorable de los últimos marcos legales. Ambos factores hacen que la situación sociolingüística del kichwa sea diglósica, es decir, política y socialmente subordinada al castellano. Esta subordinación lingüística produce y es producida por una subordinación social y económica de sus hablantes, con lo cual se puede describir bien como habitus en términos de Bourdieu (1997). Esto significa que el testimoniante habla, primero, desde una lengua subordinada, y segundo, desde un lugar de enunciación subordinado. Estas condiciones de producción son básicas para entender el discurso de la narrativa testimonial.

La situación diglósica del kichwa frente al castellano, que ha durado más de quinientos años, ha tenido como consecuencia material cambios observables en la lengua misma. Estos cambios se agrupan en lo que se conoce como mezcla lingüística (Gómez Rendón 2008) y toman la forma de préstamos léxicos y cambios de código. No profundizaremos en estos fenómenos porque su descripción es estrictamente lingüística. Sin embargo, es preciso señalar que el texto de los testimonios analizados contiene un kichwa que refleja dicha mezcla. Un análisis estadístico conducido con otros fines encontró que el conjunto de testimonios de los que forman parte los analizados en esta investigación no sólo presentan numerosos casos de alternancias de código, sino que contienen préstamos castellanos en un porcentaje que oscila entre el 25 y el 75 por ciento. Así, el kichwa de los testimonios es la prueba de siglos de violencia simbólica y lingüística ejercida sobre sus hablantes por la sociedad mayoritaria. Pero también es la prueba de la resistencia ofrecida por ellos, que pese a todo no abandonaron su lengua sino la adaptaron a las nuevas necesidades comunicativas. Por otra parte, la resistencia lingüística es también resistencia simbólica, porque los vocablos adoptados no siempre recogen la semántica de la lengua dominante sino que preservan en buena medida rasgos del significado propio de los vocablos nativos. Este proceso léxico-semántico, conocido como relexificación (Muysken 1985), subyace a la mezcla lingüística y constituye la forma de resistencia simbólica más importantes de las comunidades de habla minorizadas.

En el lenguaje, la resistencia simbólica toma la forma de estrategias etnopragmáticas que involucran distintos elementos del habla en diferentes niveles de la estructura. Una estrategia etnopragmática es el uso planificado de un recurso lingüístico con el fin de resaltar matices semánticos o posicionar al hablante dentro o fuera de su grupo de referencia. Un caso de estrategia etnopragmática puede ser la omisión deliberada de los agentes en los enunciados, con el fin de ocultar la agentividad o iniciativa política de un grupo o un individuo. El carácter 'etno' de la estrategia se debe a las metas a las que se orienta, y que reflejan o reproducen rasgos culturales y sociales propios de un grupo. En nuestro caso, este grupo puede ser el de la comunidad de origen del testimoniante, o el grupo de las comunidades indígenas de San Pablo, o incluso el grupo de los huasipungueros o de los gañanes.

Por su naturaleza, las estrategias etnopragmáticas expresan la perspectiva del hablante sobre el mundo y sobre sí mismo, y lo posicionan como miembro de un grupo a partir del cual construye su identidad. En resumen, son los mejores mecanismos para marcar y construir las identidades en el discurso. De acuerdo con nuestro análisis, las estrategias etnopragmáticas - en cuanto constructoras y/o marcadoras de identidad - se desenvuelven mejor en los siguientes elementos del discurso: 
- Los pronombres, en cuanto referentes primarios de los participantes de un evento comunicativo e índices de su identidad en las prácticas sociales.

- El discurso reportado directo e indirecto, en cuanto reproducción de las voces de otros actores sociales y medida de la polifonía e intertextualidad del testimonio.

- La comparación figurada, en cuanto reflejo de la cosmovisión del hablante plasmada en un estilo narrativo.

- Las evaluaciones, en cuanto expresión de la postura ideológica del hablante plasmada en una estética narrativa.

En el esquema de Fairclough (2008: 191-194) cada uno de estos elementos corresponde a varios aspectos del análisis textual. Así, los pronombres forman parte de la representación de los eventos sociales pero también de los estilos. Sin embargo, de acuerdo con los objetivos de la presente investigación no haremos un estudio de todos los elementos en sus diferentes aspectos textuales. Nos restringiremos sólo a los arriba señalados y los contextualizaremos en su dominio respectivo. Una vez finalizado el análisis de estos elementos, estaremos en condición de decir algo sobre la construcción de las identidades en el discurso de la narrativa testimonial y caracterizarla a través de un conjunto de rasgos lingüísticos que la distingan como género anclado en una práctica social (narrativa) que refleja una estructura de poder (Fairclough 2008: 23s).

\section{La construcción de la identidad en el testimonio: metonimia y} sinécdoque

En la narrativa testimonial analizada encontramos dos tipos de contenido: uno describe prácticas sociales (productivas, festivas, cotidianas) en el espacio público de la hacienda; otro se refiere a las experiencias del narradory su(s) grupo(s) de referencia. En esta dicotomía encontramos la primera diferenciación en la construcción identitaria.

Al describir las prácticas sociales de carácter público - es decir, aquellas que no se consideran experiencias personales o grupales se observa un ocultamiento sistemático de la agentividad de dichas prácticas. Esto se hace elidiendo todo tipo de pronombres o adjetivos posesivos con referentes personales y utilizando formas verbales indefinidas que pueden ser: 1) el participio activo /-na/, ausente en el castellano pero ubicuo en el discurso kichwa; 2) el participio pasado /-shka/, equivalente a las terminaciones castellanas en /-ado/ e /-ido/; 3) la forma del gerundio homonominal /-shpa/; y 4) la terminación cero en el singular de tercera persona. El siguiente ejemplo describe el proceso de la fiesta de esta manera, es decir, ocultando a sus actores, que permanecen sobreentendidos. Las formas relevantes aparecen en negrilla y se ofrece una traducción al castellano:

1. simanatakma karkaka, primiru konbitipak azina, conbititaka mashti istiaura parki aí plazatami chicha asi baldikunawan labakarakunawan markashka, asilla pilchiwanka pai jila dirramashpa dirramashpa rodiarka. [Duraba una semana, primero se hacía el convite, el convite era en este parque que hay ahora, en la plaza, se llevaba lavacaras y baldes llenos de chicha y con un tazón se iba convidando a todos de uno en uno]

En ocasiones se encuentran también nombres propios con referentes (metafóricamente) animados a los que corresponden formas verbales personales o impersonales. Esto se refleja, por ejemplo, en la descripción de las primeras maquinarias agrícolas introducidas en la hacienda hacia mediados de la década de 1950, las cuales reciben verbos impersonales, excepto cuando tienen referente definido y/o nombre propio ${ }^{4}$ :

2. Primeroka chay killa traktorma karka3, chaymanta kay birdi zhun diri [John Deere] shamurka3, urugama karka3, urugakuna aisashka purijunao, kay uruga aisashka purik kakpimi chay maypi pindunkuna, iskinagukuna kidashkata, pindunta katin nishka kuchushpa purinao, makinata katijunao [primero fue ese tractor amarillo, de ahí vino el John Deere verde, era una oruga, las orugas iban arrastrando, después que pasaba arrastrando la oruga, seguían las máquinas, cortando los pendones que habían quedado a los lados]

${ }^{4}$ Existe además un símil entre la máquina y las orugas propiamente dichas, según lo demuestra el uso del verbo aysana 'arrastrar', dicho de estos animales. 
El uso de formas verbales impersonales sin referentes definidos es sistemático en los testimonios analizados, a tal punto que se encuentra incluso en los pasajes castellanos de los testimonios. En este caso el hablante utiliza - como también lo hemos hecho nosotros en la traducción - el pronombre impersonal 'se', o formas de modalidad deóntica como 'hay que' o 'toca + verbo infinitivo'. Puesto que el pasaje anterior se refiere a una celebración donde participan exclusivamente indígenas, se puede pensar que esta forma de representar la agentividad no tiene nada de especial porque no es necesario identificar a los actores tratándose de una práctica social colectiva. Sin embargo, la misma estrategia reaparece en pasajes relacionados con actividades de la hacienda. En este caso se prefiere utilizar la tercera persona del singular tanto en los verbos transitivos como en los intransitivos pero sin agente definido. El siguiente es un pasaje que describe las primeras actividades de la jornada para los peones de la hacienda:

3. “A los gañanes, a ellos sí pues dabao todo completo, a los yanaperos si es que hay dabao chicha, motecito y trago, en ese tiempo para tomar chicha les hacíao beber, en ese tiempo había pues pilche que se llamaba y era hondo, en eso dabao chicha que se llama guarapo, ese lleno teníamos que tomar, chicha que se llama guarapo, ese lleno teníamos que tomar, chicha de jora pues claro"

La primera pregunta que nos hacemos al leer el pasaje es sobre la identidad del sujeto que da y hace beber a los gañanes y yanaperos. Curiosamente, no encontramos ningún individuo al que atribuir la agentividad de estas acciones ni en este ni en pasajes previos. Encontramos, sin embargo, 'la hacienda' como un agente colectivo explícito en todos los testimonios, aun cuando no haya referencia directa a sus mandos (escribientes, administradores, mayordomos, mayorales, ayudantes), como en el siguiente extracto:

4. "ese tipo de pan en tiempos de cosecha también daba la hacienda, entonces para ir a traer los panes haciendo turno nos mandabao que vayamos a traer de Zuleta, entonces teniendo caballo, en caballo necesitabao, un canasto grande o una taza así grande en eso íbamos a traer, si es que alcanza, legábamos al almuerzo si no pues a la tarde a la hora de alzarse del trabajo, a las cuatro y media o a las cinco de la tarde ya para soltar, ahí repartíao".

Estos ejemplos demuestran que se trata de una sinécdoque, con la cual se refieren las partes por el todo. Curiosamente, se excluye de esta sinécdoque la figura del hacendado, que en todos los testimonios aparece como agente individual y definido, con nombre propio. Como esencia de la agentividad y el poder, la figura del hacendado ocurre siempre personificada - individualizada e identificable - en el discurso. Así lo demuestra el acto transitivo por excelencia, aquél donde la relación gramatical entre agente, paciente y beneficiario refleja la relación social de poder que sustenta el don (Bourdieu 1997: 161-2). En el siguiente pasaje el narrador hace referencia explícita y enfática a la agentividad del hacendado en el acto del don:

5. Kutin shinallatak Galo Plaza Lassoka uyanzatami rurak karka3 gañan trabajador gentiman, gañan jazinda Zuleteñocuna, Ugsha, Angla, Topo, trabajadurkunaman uyanzata karak karkaz Galo Plaza Lassoka. [Luego Galo Plaza Lasso hizo uyanzas para para los gañanes, para los gañanes de la hacienda, los zuleteños, los trabajadores de Ugsha, Angla, Topo regaló uyanzas]

Se separa así la representación del hacendado como ícono del poder, de la representación de la hacienda como agente monolítico e indivisible: una entidad que se extiende en el tiempo y el espacio de producción y reproducción de las comunidades y cuyos agentes no son sino órganos que se mueven como parte de un todo que tiene vida propia. La corporización de la hacienda como ser unitario dotado de atributos vitales se repite en los calificativos utilizados para referirse a las características físicas del espacio, como cuando el hablante personifica la hacienda como entidad volitiva (6):

6. Tababuelamanrak andarkani, Tabauelapi dos sucresta ganarcani, chuta aypi bravo bravo jazinda cana, aymantapash dos diata morishka carcani, ese fiebre cogimushpa; [luego fui a Tababuela, en Tababuela ganaba dos sucres, chuta, ahí si que la hacienda era 
brava brava y por eso estuve dos días muerto, luego de que me cogió la fiebre]

En este caso se usa una metonimia basada en la relación de contigüidad semántica entre el lugar donde se realiza una acción y quien la realiza. La hacienda deja de ser entonces el espacio de producción y reproducción del poder para personificar ella misma dicho poder. Aun entonces, el ícono de este poder - el hacendado - no recibe en los testimonios los mismos rasgos de 'fiereza' y 'violencia' que caracterizan a la hacienda. Las razones de esta representación divergente se hallan, como hemos demostrado en otro lugar (Gómez Rendón 2001), en el uso estratégico y eficaz que este hacendado particular hacía de los símbolos festivos durante las fiestas de cosecha; pero también en el hecho de que el ejercicio directo del poder estaba en manos de los mandos medios de la hacienda mientras el hacendado aparecía sólo por breves lapsos de tiempo en los momentos culminantes del calendario productivo.

Pasemos ahora a describir la forma cómo se representan las experiencias en el testimonio: en ellas encontramos una configuración identitaria diferente y mucho más compleja que la anterior. Según señalamos, las experiencias se pueden catalogar en 1) experiencias personales, aquellas en que participa el testimoniante y que se narran con éste como único actor o actor principal; y 2) experiencias grupales, aquellas en que participa el testimoniante junto con otros individuos - a menudo de su grupo de referencia - y que se narran desde la perspectiva del grupo. Aunque en principio podemos adscribir ambas experiencias a formas discursivas con un formato lingüístico distinto, no podemos trazar una línea divisoria clara entre ambas a partir del uso de elementos como los pronombres, porque la narración de experiencias individuales se codifica siempre en el testimonio desde una perspectiva grupal, así como toda narración de experiencias grupales se anecdotiza con la perspectiva particular del narrador. Éste es el efecto de la relación metonímica propia del testimonio, donde la (id)entidad del narrador individual se fusiona con la de su grupo de referencia, del cual se constituye en vocero y representante. De esta relación se han ocupado varios estudios sobre el testimonio y la subalternidad (cf. Beverly 1999, Spivak 1988), pero hasta hoy no se ha demostrado la manera en que dicha relación se materializa en el lenguaje, no por falta de datos empíricos en los cuales llevar a cabo el análisis sino por falta de un enfoque lingüístico para el análisis social del discurso (cf. supra). El siguiente es un ensayo que busca llenar este vacío y ofrecer una metodología más rigurosa.

A partir del análisis morfológico de los textos seleccionados, cuyo propósito fue identificar los pronombres personales y sus correspondientes terminaciones verbales, se encontró que el uso del pronombre de primera persona del plural (ñukanchik y sus variantes relexificadas nutru y nusutrus $)^{5}$ junto con su respectiva desinencia verbal (-nchik) son un $75 \%$ más frecuentes que el uso del pronombre de primera persona del singular (ñuka) y su desinencia verbal correspondiente (-ni). Para un género oral que la narratología define como una historia esencialmente personal, la presencia ubicua de un sujeto colectivo no deja de sorprendernos y constituye prueba clara de la función metonímica o sinecdótica del discurso testimonial, por sobre aquella de carácter reflexivo. Esta relación implica, sin embargo, mucho más que una identificación unívoca entre el 'nosotros' de testimonio y el grupo de referencia del hablante, por la sola razón de que este grupo no es único e invariable en el discurso. Mejor dicho, no se trata de uno sino de varios grupos de referencia. Como demostraré enseguida, el 'nosotros' abarca en los testimonios una cantidad sorprendente de colectivos sociales según la perspectiva que asuma el narrador. Más todavía, como el sujeto narrativo ejerce su función autoreflexiva a partir de su identificación sinecdótica con el 'nosotros', el testimoniante va definiendo su identidad en diferentes aspectos de la praxis social, a partir de la variedad de entidades referidas por el 'nosotros'. Una exploración preliminar de esta estrategia se llevó a cabo en Gómez Rendón (2008: 127-141).

${ }^{5}$ Es posible plantear la adopción de estas formas relexificadas a partir de los pronombres castellanos como una forma de etnogénesis para hablantes que se identifican con el mundo hispano pero que al mismo tiempo mantienen sus relaciones con su comunidad, dando origen a hablas mezcladas como las de uno de los testimoniantes cuya contribución analizamos aquí. Al respecto, véase Gómez Rendón (2008). 
Mediante el análisis de una biografía recogida en la misma zona, se encontró que en el relato dos grupos de referencia se fusionaban en uno a lo largo de la línea biográfica y servían de referencia al hablante para construir un sujeto narrativo que alternaba entre el ‘yo' y el ‘nosotros'. Lo limitado de la investigación y las herramientas utilizadas entonces impidieron, sin embargo, llegar a conclusiones más específicas.

Alanalizar el pronombreñukanchik 'nosotros'y sus desinencias verbales encontramos casi una veintena de posibles referentes, que se agrupan a continuación según tres criterios semánticos:

Cuadro 1. Referentes del pronombre plural de primera persona (ñukanchik)

\begin{tabular}{|c|c|c|}
\hline GENÉRICO & ÉTNICO & ECONÓMICO \\
\hline $\begin{array}{l}\text { - Los seres humanos } \\
\text { - La familia } \\
\text { - La comunidad } \\
\text { - Los jóvenes } \\
\text { - Los hombres } \\
\text { - Las mujeres } \\
\text { - Los antiguos } \\
\text { - Los niños } \\
\text { - Los festejadores } \\
\text { - Los interlocutores }\end{array}$ & $\begin{array}{l}\text { - Los indígenas las comunidades } \\
\text { aliadas en la lucha ritual } \\
\text { - Las comunidades cayambes de } \\
\text { San Pablo } \\
\text { - Las familias de la comunidad }\end{array}$ & $\begin{array}{l}\text { - Los gañanes } \\
\text { - Las conciertas } \\
\text { - Los yanaperos } \\
\text { - Las servicias } \\
\text { - Las almozeras }\end{array}$ \\
\hline
\end{tabular}

Fuente: elaboración del autor.

Es posible que esta variedad de referentes, ya de suyo importante, pueda ampliarse si analizamos un corpus más grande de testimonios. De cualquier manera, algunos referentes - en negrilla - se repiten sistemáticamente en todos los testimonios, alternando con el pronombre de primera persona singular para marcar la relación del hablante con un grupo de referencia. A continuación analizamos los más importantes.

La familia aparece como uno de los referentes principales en los testimonios analizados, cosa nada sorprendente si tomamos en cuenta que es el núcleo de producción y reproducción social más importante. Cabe señalar, sin embargo, que se trata de una familia extendida, que puede incluir relaciones de parentesco simbólico como los achik taitacuna o padrinos. En el siguiente pasaje se ilustra cómo el testimoniante se identifica a partir de este grupo de referencia:
7. Nutruska pay chapariashpa ishtankiruka, jala!, dus diata kamarkani pulmunwan; dijuntu taita Pabluwan kumbak karkanchi, il primiru butarishka dus diyata, il mijurakpi, il chancha chanchalla tunilpi pararikpica, ya güilta yu kayandi butarini, aymantaka ayudakkuna ansikarin, Luisitu Palacio tayta, Echi taitallatak, isikuna güilta nutruska ayudana, nutrus turbarinajuna, utru familia binin, utru familiapish binin; unuman danjungakamanka, ya güilta utru familiaka nu kumishpa andan; utruman atendijungamanka, ya güilta utru familiaka obligacionwan binin [Nosotros1P vigilábamos, éramos estanqueros ${ }^{6}$ iay! Yo1S sí que cuidaba dos días con esmero, nosotros1P trabajábamos con el difunto taita Pablo, él primero se enfermaba el dos días, y cuando mejoraba con dificultad paraba los toneles, luego me enfermaba yo1s dos días después y me ayudaban, el taita Luisito Palacio, el taita Echi, luego cuando caían ellos les ayudábamos nosotros ${ }_{1 P}$, cuando ya no avanzábamos, venía otra familia y luego otra familia más, hasta le atendían a uno1S, le daban de comer, atendían a otros, luego venía otra familia para cumplir con su obligación.]

Dos observaciones sobre este pasaje. La primera tiene que ver con la alternancia de los pronombres. El hablante empieza identificando un actor colectivo del cual forma parte ('nosotros') y se sitúa enseguida como miembro ('yo'). Utiliza esta estrategia tres veces seguidas $(1 \mathrm{P}, 1 \mathrm{~S} ; 1 \mathrm{P}, 1 \mathrm{~S}, 1 \mathrm{P}, 1 \mathrm{~S})$ a fin de establecer un marco de referencia para la siguiente narración. La alternancia de formas pronominales en cláusulas consecutivas es un mecanismo lingüístico común para que el sujeto enunciado se posicione dentro de su grupo de referencia.

La segunda observación tiene que ver con el uso de la sinécdoque para representar la familia: los nombres propios de las personas enunciadas representan no sólo a individuos sino también a sus respectivas familias. Esta relación de inclusión posiciona al hablante como miembro y representante de su familia, como los demás actores mencionados.

${ }^{6}$ Dícese del que cuida o trabaja en un estanco. Los estancos en la zona de San Pablo eran lugares donde se producía chicha o alcohol para la venta o para distribución en ocasiones festivas. 
Otro referente del pronombre de primera persona del plural son los grupos de edad. Unas veces agrupan a los jóvenes - cuando el hablante relata una experiencia de juventud - otras veces agrupan a los mayores - cuando el hablante compara el pasado con el presente. El siguiente extracto resalta las diferencias en la preparación de la chicha en el pasado y la actualidad:

8. Kunan kunanpish jorata chayrianimi, ña kimsa watayma chusku wataima kanka, shina unay jorata chayni; mushuk jorakuta rurashkachayari, watan watan jorapash tiyanmi. Nukanchik tiympu kashna jorarina, chulpiyachishpa chucllushna chaymi mishkitapash, chaymi kulurtapash charin, chulpiyashka, chaymi saburtapash charin. [Ahora todavía preparo jora, ya son tres, cuatro años, hace tiempo que preparo jora, una vez se hace jora, ya hay para el año siguiente, en nuestro tiempo así preparabamos la jora, luego de endulzar, ese como choclo, dulce, tiene ese color, ya endulzado, ya coge sabor]

El pasaje inicia con el narrador en presente y continúa con el grupo de referencia en pasado. En este caso los polos de referencia están representados por: 1) el adverbio temporal kunan 'ahora' y la terminación verbal de primera persona singular (-ni/; y 2) el adjetivo posesivo de primera persona plural que se adjuntó a tiympu 'tiempo'. Con el presente como punto de partida, el referente del posesivo se identifica con el pasado, o para ser exactos, con quienes realizaban una práctica en el pasado y ahora son ancianos. También el pasado puede ser el punto de partida para definir el grupo de referencia y la inclusión del hablante. Esto ocurre en el mismo testimonio unos pasajes antes:

9. Berna taitaka ñukanchikpakka jipa wamprakunami ñukanchik, sultirakaura, paika uchilla wampra wawakuta aparishka, shina karian. [Papá Bernardo (llevaba) para nosotros, nosotros éramos jóvenes, (yo) era soltera, él llevaba a jóvenes y niños, así era].

El referente del ñukanchik son los jóvenes y los niños, entre los cuales se ubica la hablante, que para entonces era soltera. Nótese que el pronombre de primera persona singular está implícito. El contraste se marca entre el grupo al que pertenecía entonces la hablante (joven y soltera) y el grupo al que pertenece ahora (mayor y casada).

Hasta aquí hemos visto referentes de carácter genérico a los que puede aludir el pronombre y sus desinencias verbales. Sin embargo, los referentes más numerosos en los testimonios son específicos, de carácter étnico y económico. Miremos este ejemplo:

10. aurakarin akí balli jazindakunamankarin atadutapash yanu sakanka, puru adubillu kashkama, Intaman ataduka sakan, isi tiympoka bunki pallakunakunaka nutru manullama kana, ya después isi nigusiantikuna dintrashpamari, ya miskinashpa yanu chukchi karianchi, asishpaca chukchishka bulsakukunapika asi as binik karkanchi. [ahora en cambio ya no sacan atados grandes de las haciendas del valle, sólo pequeñitos, a Intag llevan atados grandes, en ese tiempo nosotros recogíamos los residuos de las cosechas a mano, luego cuando entraron los negociantes, ya mezquinaban y no nos dejaban recoger, así apenas llevando algo en los bolsillos, así no más hacíamos].

El contraste en este caso se marca entre los negociantes que 'mezquinan' los residuos de las cosechas de la hacienda y quienes tenían la costumbre de recogerlos para completar su dieta alimenticia. Estos últimos eran sobre todo yanaperos, pero también algunos gañanes o peones de hacienda. Aunque el narrador fue yanapero de la comunidad de Casco, el referente en (10) no son los yanaperos de su comunidad, pues a las haciendas de la zona acudían yanaperos de otras comunidades, inclusive indígenas otavaleños. A partir del contraste que se establece con los negociantes blanco-mestizos, se colige que el referente del 'nosotros' son los indígenas en cuanto grupo étnica- y culturalmente diferente de los negociantes. A parte de esta referencia implícita, no encontramos en los testimonios un elemento léxico como 'los indígenas' o 'los runas'. Al contrario, encontramos con mucha frecuencia el vocablo 'gente', que aparece en kichwa fonológicamente adaptado (ginti) pero también en castellano. He aquí un ejemplo, extraído a continuación del precedente: 
Subalternidad y contrahegemonía en la narrativa testimonial kichwa de la sierra norte del Ecuador

11. puirkugukunaima asi asi murishkagukunata kañaman andakpi patronyayakuna tiranlla, isigukunatapash gintiman dan, isigukunatapash manticagukunata azishpa traimungapak nu ispisuyanchu, pai chuyalla kanlla, nu valinchu, yangamantama antuju chicharrungukunaima azishpa traimun. [los cerdos que morían por andar en las cañadas los patrones los tiraban, les daban a la gente, con esos se hacía manteca para llevar, si no esperaba y quedaba aguado, no valía y para pasar el antojo se hacía chicharron para llevar].

Este ejemplo sirve de punto de partida para un estudio semántico del vocablo 'gente' en los testimonios. Lo primero es que el término no se refiere a la gente en general sino a la gente indígena. Al respecto es interesante mencionar un fenómeno relacionado. El kichwa ecuatoriano perdió a lo largo de su historia el contraste entre un plural inclusivo de primera persona y un plural exclusivo de primera persona, quedando solamente la primera forma?. Esto significa que el kichwa ecuatoriano carece de una forma gramatical (un pronombre y su respectiva desinencia verbal) que indique un 'nosotros' que excluye al interlocutor u otro grupo de referencia. Este vacío gramatical parece llenarlo satisfactoriamente el préstamo castellano ginti. Ahora bien, aunque el referente de 'gente' en el pasaje anterior parece ser 'los indígenas' como grupo étnico, resulta más exacto definir el referente como un colectivo que ocupa una posición determinada en la sociedad. Esta posición, según los ejemplos previos, es esencialmente subalterna: 'gente' no se refiere a cualquier colectivo étnico sino al conjunto de los individuos que subsisten con los residuos de la producción de la hacienda. Pero además, el término 'gente' utilizado para referirse a un colectivo en condición subalterna desafía el discurso racista del castellano andino porque insiste en la condición humana y racional de sus miembros, aun cuando aquél asigna rasgos negativos a la subalternidad expresada como otredad cultural o lingüística ${ }^{8}$.

7 Este contraste se mantiene en otras variedades del kichwa, sobre todo en Perú y Bolivia.

${ }^{8}$ En el discurso racista es común encontrar expresiones que implican hablar o hacer cualquier cosa 'como la gente', en contraposición a lo que hacen los animales.
Por otro lado, la exclusividad del término ‘gente’ sirve también para distinguir identidades parciales dentro de una condición social o un colectivo étnico. Leamos cuidadosamente el siguiente pasaje:

12. Sanrrukicaka, isin adilanti binikuna, isin buskak kana. Isitapash dismayachirianchin, isita dismayachikpika ya ilkunapish kurrin, más siguirkanchi nusutruska. Builta Compania nutru ladu, Companiawan ajuntarishpakarin iju! Companiaca nutru ladu cana, Camuendoimapish, Companiapish isi karguyuk dizishka, kapitán dizishkachari montashka, asi bandirata llenachishka shina vinina puntapi, nusutrus asi kuriuzuyashpa, unu, dusma, trisma andashpaka isikunawan chapurishpa, aytaka atrás isi Compañía [...] ayka Compañía guangudo chaupipi, bandirata tinichikpika, bandirandi vinik karianchi, difunto Baltaguwan, así ay nutru gintika ya inkontramun parkipi, aymantaka iju! taytiku Companiawanka chapurishkaka, nusutrus adilantashka, Compania bandirakashkawan siguishka, pay Sanrrukitaca, Pusakuta parabajuman, kingrai punishpa dijarianchi, Companiawan, Camuendowanca nutru partimi, Araqueñopish nutru partimi, nusutruswan agarrakpi, Araqueñokunapish Ilenamunallan [Los de San Roque iban adelante, esos buscaban pleito, cuando ya les vencían, ya vencido, ellos también corrían, y nosotros les seguíamos atrás, por otro lado, los de Compañía estaban de nuestro lado, juntándonos con los de Compañía, ayayay, los de Compañía estaban de nuestro lado, también los de Camuendo, los de Compañía eran los jefes, el capitán iba montado, así lleno de banderas iba en la punta, nosotros así de curiosos andábamos con ellos, atrás de los de Compañía, luego los guangudos de la Compañía iban en el medio con las banderas, así veníamos con banderas, con el difunto Baltazar, entonces encontrábamos a nuestra gente en el parque, luego, ayayay, nos mezclábamos con los de Compañía, nosotros íbamos adelante, nos seguían los de la Compañía con las banderas, y ahí les dejábamos mal parados a los de San Roque y los de Pusaco, porque los de la Compañía y de Camuendo estaban de nuestro lado, los de Araque estaban de nuestro lado, los Araqueños venían a completar cuando nos agarrábamos a pelear] 
El pasaje corresponde al relato de una lucha ritual celebrada hasta mediados de los años sesenta en la parroquia de San Pablo del Lago entre las comunidades de arriba (Topo, Casco, Angla, del pueblo cayambe, y Compañía, Camuendo y Araque del pueblo otavalo) y las comunidades de abajo (San Roque y Pusaco). El relato empieza identificando un sujeto colectivo que representa las comunidades de Zuleta (Topo, Casco y Angla) y se distingue a lo largo del relato de las comunidades pertenecientes al pueblo otavalo. Aún cuando algunas comunidades otavaleñas pelearan del lado de las comunidades de Zuleta - llegando en algún momento a fundirse ambas en un sujeto agente ('así veníamos con banderas') - la identidad de las comunidades cayambes se marca sistemáticamente con el pronombre 'nosotros' y con la frase ‘nuestra gente’. En este caso el posesivo ‘nuestra’ delimita la extensión semántica del vocablo ‘gente' al grupo de referencia del hablante, que abarca todas las comunidades cayambes de la cuenca del San Pablo. El narrador se identifica así como miembro del pueblo Cayambe (nusutrus 'nosotros'), histórica y culturalmente distinto del pueblo Otavalo (ilkuna 'ellos'). La dicotomía nosotros-ellos se expresa también en el uso de un vocablo diferente para cada grupo: los otavaleños reciben el mote de guangudukuna 'guangudos' por la trenza y se distinguen de los muchukuna ‘mochos' que llevan el cabello corto. El uso de ambos términos se ilustra con el siguiente ejemplo:

13. Sanjuanta bailashpaka, abajo Pusakopika, juishta macanajuc karka dizishpa, kaynanilla, uno ruku guangudu tayta parlakuna, muchukunataka hashta pichia rumillawanta kallpachikllama karkanchik dizikunka. [Luego de bailar los sanjuanes, abajo en Pusaco, 'peleaban duro' me decía ayer no más un viejo otavaleño, 'les hacíamos correr a los cayambes con piedras' decía].

El discurso reportado directo que recoge las palabras del otavaleño le identifica como miembro del grupo contendiente (los cayambes) al que pertenece el hablante. Sobre el uso de este mecanismo lingüístico para representar las identidades en el discurso hablaremos en la siguiente sección. Analicemos ahora el uso del pronombre de primera persona plural para referirse a los dos grandes grupos de trabajadores de la hacienda.
Las relaciones laborales entre las comunidades indígenas y la hacienda se definían según la 'pertenencia' o 'no pertenencia' del trabajador a la hacienda. Esta pertenencia no sólo significaba vivir en huasipungos dentro del espacio de la hacienda sino también entregarle la mano de obra única y exclusivamente a ella. La mano de obra era masculina y femenina e incluía prácticamente todos los grupos de edad. Los trabajadores varones bajo relación de dependencia se llamaban 'gañanes', mientras que las mujeres recibían el nombre de 'conciertas' cuando eran casadas, y de 'servicias' cuando eran solteras. El no pertenecer a la hacienda implicaba una relación laboral de relativa independencia para el trabajador pero también un acceso restringido a ciertos beneficios como el uso de pastizales y fuentes de agua. Los trabajadores sin relación de dependencia eran conocidos como 'yanaperos' y trabajaban para la hacienda especialmente en tiempos de cosecha o cuando la mano de obra huasipunguera era insuficiente. El yanapero era siempre un varón adulto, casado y con familia. Su mujer y sus hijos participaban indirectamente en las actividades de la cosecha y podían recoger sus residuos (actividad conocida en kichwa como chukchina, véase extracto 10). Como señalamos en su momento, las tres personas que ofrecieron los testimonios que analizamos desempeñaron funciones diferentes: Bernardo fue huasipunguero o gañán; Segundo fue yanapero; y Amalia fue servicia. Analicemos pequeños extractos de sus testimonios donde aparece su relación laboral con la hacienda:

14. Intunsis, chayta disbaratashkamantami, chay watamanta pachami, finadu Galo Plaza Lasoka, ñukanchik patronka anchuchirka, ñana churarka gintita maltratakta rikushpa, paypak prinsipal trabajadur irriruta maltratakta rikushpa, paypa prinsipal trabajadur irriruta maltratakta rikushpa anchuchirka, chay puncha, chai watamanta pacha ñana churashpa turutaka, intunsis chaytami ñukanchik rikurkanchi. Kutin shinallatak Galo Plaza Lassoka uyanzatami rurack karka gañan trabajador gentiman, gañan jazinda Zuleteñocuna, Ugsha, Angla, Topo, trabajadurkunaman uyanzata karak karka Galo Plaza Lasoka, primiru uyanzami karian, ñuka rikushkanimi, kaymi karak karka, jatun tanta, ñukanchik kunan kay matrimuniukunapi miza tanta ninchi, burru tanya ninchi. [Entonces, por que hirió a 
Subalternidad y contrahegemonía en la narrativa testimonial kichwa de la sierra norte del Ecuador

esa persona, desde ese año, el finado Galo Plaza Lasso, nuestro patrón, retiró (las corridas de toros), al ver que herían a la gente y que su principal trabajador, el maestro herrero, salió herido, quitó los toros desde ese año, eso es lo que vimos. Luego Galo Plaza Lazo hizo las uyanzas para para los trabajadores gañanes, para los gañanes de la hacienda, a los zuleteños, los trabajadores de Ugsha, Angla, Topo regaló las uyanzas, primero en las uyanzas, según ví, sabían dar pan grande, lo que nosotros ahora llamamos pan de matrimonio, lo que llamamos pan de burro] (Bernardo, gañán).

15. Uyazangapakka Zuletaman andana, chichataka aki gañankuna azina, dika numbradumi builta kargashpa andak karianchi, nusutrus kada kazamanta, isi kazamanta, isi kazamanta dizishpami mayural nombrak binin, ya uyanzaman andangapakka nusutrusmi kargashka andak karianchi Zuletamanca chicha maltakunawanka. Asi andakarianchi. [Iban a Zuleta a las Uyanzas, los gañanes hacían chicha y andábamos cargando y repartiendo en cada una de nuestras casas, 'esa casa' decía el mayoral, luego para ir a uyanzas íbamos a Zuleta cargados de maltas de chicha. Así andábamos] (Segundo, yanapero)

16. Ñukanchik juilluta rishka tiympumanta pacha, uyanzaka siymprimi Zuletaman rikuna, chayka ima timpuradapi uyanzataka rurak karkanchika, chayka kuzicha tukurikpicha uyanzajuna, ima tiympupichari uyanza karianchiyari, chayka, ñukanchik sultira shikan; ñukanchik sultiraka ña juillota rishpakka, sirvisiakuna, chashna, ñukanchik chashna almuzira, chashna kuchikamakkuna, lichikamakkuna. [En ese tiempo nosotros íbamos bastante, siempre íbamos a Zuleta, entonces hacíamos uyanzas en cualquier temporada, cuando acababa la cosecha, hacíamos uyanzas, en cualquier temporada hacíamos uyanzas, entonces nosotras las solteras aparte, nosotras las solteras íbamos bastante, las servicias, nosotras las almozeras, las cuidadoras de chanchos, las lecheras] (Amalia, servicia)

En todos estos pasajes encontramos una o más formas del pronombre de primera persona plural, cuyo referente es distinto según el caso. En el relato de Bernardo, el referente del pronombre (los gañanes de la hacienda) se recupera a partir de las frases nominales ‘nuestro patrón' y ‘trabajadores gañanes'. Nótese el uso del patronímico 'zuleteños', que se refiere a todos los trabajadores del complejo de haciendas de Zuleta, sin importar su relación de dependencia. Debido a la extensión del patronímico9, el hablante especifica la clase de 'zuleteño' que recibe las uyanzas del patrón adjuntando dos sustantivos: el gañan de la hacienda. Nótese también el uso del colectivo 'gente' en la frase gañan trabajador ginti, a pesar de que resulta un pleonasmo y parece no añadir nada al significado de 'trabajador gañán'. Como en los casos arriba analizados parece que la función del sustantivo colectivo es exclusiva porque marca la diferencia con los trabajadores que no son gañanes (los yanaperos).

Sin embargo, más adelante en este mismo testimonio el hablante agrupa a los yanaperos como 'gente de yanapero', lo cual nos obliga a descartar la primera hipótesis y retomar la primera función del colectivo, la de reafirmar la condición de persona humana de quien trabaja para la hacienda sin importar su relación laboral. Pero además, el uso de 'gente' para referirse a todos los peones de la hacienda reafirma los lazos étnicos y colectivos entre gañanes y yanaperos. Estos lazos se hacen evidentes en el testimonio de Segundo (yanapero), quien relata que los gañanes de Zuleta preparaban la chicha para los yanaperos y éstos iban repartiéndola junto con el mayoral casa por casa. Las desinencias verbales ayudan a marcar en este caso el contraste entre ambos grupos de trabajadores: la frase gañankuna azina, pese a llevar un sujeto con referente plural definido, utiliza un morfema impersonal de participio activo, mientras que la frase builta kargashpa andak karianchi, pese a que no presenta pronombre alguno, lleva la primera persona de plural. El pronombre plural aparece más adelante (nusutrus) para explicitar la referencia al grupo de los yanaperos.

${ }^{9}$ El uso de patronímicos es prolífico a lo largo de los tres testimonios analizados aquí. Con la diferencia de que éstos aparecen directamente sin núcleo nominal, como en el caso del extracto (12), donde Sanrruki (San Roque), Compañía y Camuendo - todas comunidades otavaleñas de la cuenca del San Pablo sirven se refieren a sus miembros participantes en las luchas rituales, en un nuevo ejemplo de sinécdoque. 
Por su parte, el análisis del testimonio de Amalia demuestra cuán útil puede ser el pronombre ñukanchik para ayudar al hablante a situarse en distintos grupos de referencia. El referente del primer pronombre es genérico y abarca a las mujeres, aunque no a todas las mujeres, sino exclusivamente a las trabajadoras de la hacienda. El segundo pronombre se refiere a las llamadas ‘servicias’ o trabajadoras jóvenes. Finalmente, el tercer pronombre abarca un grupo específico de servicias, las almozeras, mujeres que llevaban la comida a los mayordomos y mayorales que trabajaban en las sementeras. De esta manera, el pronombre precisa la identidad del grupo de referencia de la hablante y la caracteríza al mismo tiempo como mujer, trabajadora, y almozera.

Antes de terminar esta sección, nos referiremos a otros usos del pronombre ñukanchik según se observa en los testimonios. Éste no sólo obedece fines de identificación sino también de marcación del discurso. Nótese que en buena parte de los extractos citados aparece la frase ña chashna kausanchik o su versión relexificada asimi andak karkanchi, ambas con el significado de ‘así vivíamos' o ‘así era nuestra vida'. Su aparición es sistemática en los testimonios, aunque ocurre exclusivametne en la narración de experiencias individuales y/o grupales y siempre al cierre de un pasaje (véase, por ejemplo, el extracto 15). Esto sugiere que la frase funciona como un recapitulador del discurso precedente, pero a diferencia de los casos hasta aquí discutidos, este ñukanchik es de mayor extensión: a través de él se completa la función metonímica del sujeto narrador con cada uno de los distintos grupos de referencia mencionados en un pasaje.

Más allá de confirmar la metonimia del sujeto narrador con su grupo de referencia, la forma creativa en que aquél utiliza el pronombre 'nosotros' hace de este mecanismo una de las estrategias etnopragmáticas más importantes para construir y marcar las identidades en el discurso. Sin embargo, su función referencial estaría incompleta si no fuera por la presencia de otra estrategia hábilmente utilizada por el testimoniante: el discurso reportado directo. Sobre la manera en que éste matiza la intertextualidad del texto y su carácter dialógico tratamos en la siguiente sección.

\section{El carácter dialógico del testimonio: polifonía con responsabilidad comunicativa}

Otra afirmación muy frecuentemente asociada con el carácter del testimonio es la polifonía, entendida como la presencia de más de una voz en el discurso o la coexistencia de varias voces junto a la voz del testimoniante. Relacionada con la polifonía está la idea de intertextualidad y el carácter dialógico del testimonio. Sin embargo, como en el caso de la metonimia, esta característica se adscribe con demasiada frecuencia sin un debido análisis del lenguaje que la respalde. Esta sección analiza una estrategia etnopragmática directamente vinculada con la polifonía: el discurso reportado directo. Para empezar debemos mencionar una característica del kichwa que lo distingue del castellano y que está estrechamente relacionada con la polifonía. En muchas lenguas del mundo se marca obligatoriamente la fuente de información de los enunciados. El kichwa es una de ellas, para lo cual utiliza tres mecanismos: 1) marcar el enunciado con el morfema de evidencia directa /-mi/, que indica que el informante ha sido testigo ocular del evento que relata; 2) marcar el enunciado con el reportativo indirecto nin, que indica que el hablante reproduce con sus propias palabras información que obtuvo de terceros; y 3) marcar el enunciado con el reportativo directo nishpa ${ }^{10}$, con la cual el hablante reproduce la información obtenida de terceros utilizando las palabras de éstos. Éste último mecanismo se llama discurso reportado directo y existe en todas las lenguas del mundo. Éstas difieren, sin embargo, en dos aspectos importantes: 1) aunque todas las lenguas pueden indicar la fuente de la información de sus enunciados, sólo algunas lo hacen a través de mecanismos gramaticales; y 2) en las lenguas que marcan gramaticalmente la fuente de información, el hacerlo no es una cuestión de elección sino de obligación. Una de estas lenguas es el kichwa, en lo que se distingue del castellano, donde marcar la fuente de información es una opción que tiene el hablante pero nunca una obligación comunicativa"1.

\footnotetext{
${ }^{10}$ Nótese que tanto la forma nishpa 'diciendo' como la forma nin 'dizque'

${ }^{10}$ Nótese que tanto la forma nishpa 'diciendo' como la forma nin 'dizque'
provienen del verbo kichwa ni- 'decir'. Sin embargo, en variedades del kichwa con un alto grado de mezcla con el castellano, la raíz del verbo decir ha sido reemplazada por el préstamo dizi- 'decir', con el cambio consiguiente en las formas reportativas, que entonces se convierten en dizishpa y dizin.

${ }^{1}$ Una manera de hacerlo es, por ejemplo, a través del adverbio 'dizque', o también del pretérito perfecto compuesto en el castellano andino ecuatoriano (cf. Haboud 1998).
} 
Subalternidad y contrahegemonía en la narrativa testimonial kichwa de la sierra norte del Ecuador

Cabe entonces esperar que la narrativa testimonial kichwa haga uso prolífico del discurso reportado directo e indirecto ${ }^{12}$.

El discurso reportado directo/indirecto efectivamente es frecuente en los testimonios. Sin embargo, su distribución depende del tipo de material enunciado. Se encuentran casos de discurso reportado directo/indirecto única y exclusivamente en los pasajes que tienen que ver con experiencias individuales y/o grupales. Es preciso recordar en este punto que si bien el efecto colateral del discurso reportado directo/indirecto puede ser asignar un valor de verdad a un enunciado, su función no es precisamente ésta sino tan sólo marcar la fuente de la información. Observemos el siguiente ejemplo:

17. Dusi añumanta Vallimanka andarkani yarirka, chikiturakmi andarkani, iskwilapi andakushpallatami taytikuka llibashpa andawarka, juyaypami ñuka wañushkapica puripanga kullkimantaima, kaypika maypi kulkita ganashpata, ñuka kawsakushpallata yachachisha dizishpa Vallimanca llibashpa andarka. Llorai Iloraimi andarkani, nu insiñarishpa, Tapiapamba jazindaman llibarka, simanakuta kashpalla traishpa vinirka builta, unkui kujinka dizishpa, isika nu insiñarishpa, gallina, así gallinira limfiaikukunapi asi parki azishka, asikukunata limfiashpallami andak karkani, dus realiskuta ganashpa biniriani. [Me acuerdo que a los doce años me fui a lbarra, todavía era chiquito, todavía iba a la escuela, mi papá me fue llevando, yo fui con gusto por ganar algún dinero, 'cuando ganes dinero allá, viviendo aprenderás' diciendo me llevó a Ibarra, llorando llorando me fui, no me enseñaba, me llevó a la hacienda de Tapiapamba, luego de una semana regresó a traerme, diciendo 'va a cogerte la enfermedad', como no me enseñé ahí, trabajaba limpiando lo de las gallinas, los gallineros, en el parque, eso limpiaba y venía ganando dos realitos.]

El testimoniante utiliza el discurso reportado directo para reproducir las palabras de su padre.

\footnotetext{
${ }^{12}$ En esta sección nos ocupamos exclusivamente del discurso reportado directo e indirecto en los testimonios. Un estudio lingüístico de la evidencia directa e indirecta es Gómez Rendón (2006).
}

Aún cuando muy probablemente no sean las mismas palabras que aquél pronunció, el propósito del hablante no es tanto hacer eco de ellas sino explicar su temprana salida de la escuela, que obedeció a una decisión que no fue suya sino de su padre. El uso del discurso reportado directo como explicación es común en kichwa y se encuentra en todos los testimonios. Aún así, ésta no es su función principal, la cual se observa mejor en el siguiente pasaje:

18. chayka taytaka, nik kashka, kanpak mamaka ñukapakmi, kanpak mamawan puñurkani nishpa wawakunataka mulistak kashka, chaymi chay wawakuna ña wiñarishpaka, chay taytaka, kanmi shina nik karkanki ñuka uchilla kakpika nishpa shukllankaman japishpa makasakishkanka nin, maikanlla nishkata trankashpa shayarishpa makasakishkanka nin. [Entonces ese hombre ha sabido molestar a los niños diciéndoles 'su mamá es mía, yo dormí con su mamá', pero cuando los niños crecieron, cada uno dizque le cogía y le golpeaba diciéndole 'tú eras el que me decía así cuando era pequeño', cualquiera que le encontraba dizque le agarraba a golpes]

A través del discurso reportado directo el hablante presenta el relato como una especie de diálogo entre dos personajes, dándole un matiz de realidad inmediata a manera de actuación (enactment). El carácter performativo que añade al testimonio el discurso reportado directo ayuda a crear polifonía y diálogo entre los personajes. Sin embargo, esto no significa que el hablante se atribuye haber escuchado directamente las palabras citadas: no, ellas provienen de terceros, según indica el reportativo indirecto nin 'dizque'. De esta forma el testimoniante sigue las reglas comunicativas de su medio social, marcando obligatoriamente el origen de la información que pone en boca de terceros. Esta es una diferencia esencial con las formas del género autobiográfico.

Las voces que aparecen en el discurso reportado directo pueden asignarse a distintos actores sociales, pertenezcan o no al grupo de referencia del hablante. No obstante, en el corpus analizado es más frecuente que el discurso reportado directo corresponda a individuos fuera del grupo del hablante. El siguiente ejemplo - citado 
ya a propósito de los gentilicios ‘guangudu' y ‘muchu' - ilustra el uso de este mecanismo para marcar distancia entre el sujeto narrativo y uno de los personajes del testimonio:

19. Sanjuanta bailashpaka, abajo Pusakopika, juishta macanajuc karka dizishpa, kaynanilla, uno ruku guangudu tayta parlakuna, muchukunataka hashta pichia rumillawanta kallpachikllama karkanchik dizikunka. ['Luego de bailar los sanjuanes, abajo en Pusaco, peleábamos duro' me decía ayer no más un viejo otavaleño, ‘les hacíamos correr a los cayambes con piedras’ decía]

La diferencia étnica entre cayambes y otavaleños, establecida previamente en el relato, toma forma a través de voces separadas. Una es la voz del testimoniante (que pertenece al pueblo cayambe); otra es la voz del personaje (que pertenece al pueblo otavalo). De esta forma el narrador se distancia del personaje atribuyéndole voz propia y marcando una diferencia de opinión: la afirmación del personaje en (19) contrasta con la afirmación del testimoniante en (12), según la cual eran los Cayambes quienes ganaban la batalla ritual a los Otavaleños y no lo contrario. Lo interesante es que pese a ser de otra opinión, el testimoniante otorga espacio a la diferencia, marcando en cada caso la fuente de una afirmación. Al respecto, Fairclough (2008: 192) afirma que un aspecto importante de los textos es su orientación hacia la diferencia. Dicha orientación puede ser de apertura, aceptación o reconocimiento de la diferencia, como en el diálogo abierto; de acentuación, a través de la polémica y la lucha por el significado; de resolución, a través del consenso; o de interrupción, con el fin de resaltar la comunión y la solidaridad. El ejemplo antes mencionado apunta al primer escenario: integrando diferentes voces en un tejido dialógico, el testimonio ni acentúa, ni resuelve, ni interrumpe la diferencia, tan solo la presentar y la reconoce. Nos parece, por lo tanto, un discurso más consecuente con la diversidad porque practica la interculturalidad con base en la intertextualidad. Esto no significa que el testimonio no resalte la diferencia para denunciar, siendo ésta precisamente su característica más importante como discurso político. Así podemos constatar en el siguiente ejemplo:
20. kaynallamari Pito tiyu kunbirsajun3, aurapika Vallipipash algunuslla, algunus asi chiquitu haciendagukunalla abin dizin, aikunapika ufisinapi tiyak mishumanshinami kafita cabashpa imatapash na mikuna abikpica, lashtiman yarjai purinchi dizin. saruncunaca, siquira jaku chapuguta kumishpa ña aguantarinami, jaku chapuguwanka, auraka ufisinapi sintangapa andak mishumanshina kafita unulla panguanmari dalin nin [ayer no más conversaba el tío Pito que todavía dizque hay en el Valle algunas haciendas pequeñas, en ellas cultivan café para los mestizos que trabajan en las oficinas, $y$ 'como no nos dan de comer, nos morimos de hambre' dicen, 'siquiera comiendo chapo se aguanta, con chapo siquiera', en cambio dizque a los mestizos que están sentados en la oficina les dan café con pan]

En el ejemplo la marca del discurso reportado directo (dizin 'dicen') concuerda en número y persona con los sujetos referidos, aquellos que trabajan para las pequeñas haciendas del valle de Ibarra sin recibir una sola ración de alimento durante toda la jornada. La voz de los trabajadores explotados contrasta con las noticias que tiene el hablante de que los mestizos que trabajan sentados en las oficinas reciben regularmente su comida. El testimoniante refuerza la denuncia actuándola a través de las palabras de los afectados, pero no deja de cumplir su obligación comunicativa de indicar la fuente de información en lugar de solo enunciarla.

El discurso reportado directo es tan sistemático en la narrativa testimonial que aparece incluso en los pasajes castellanos. En este caso el hablante introduce enunciados en kichwa $^{13}$ y repite el verbo reportativo al principio y/o al final de los mismos:

21. también el niño de loa formaba como aporte solidario de los familiares o amigos para organizar la fiesta, ellos decían ñuca huahuata curasha loapac, decían.

22. “compañashunchi yamta mingaita" decían ${ }^{R P}$, vamos a minga de leña decían, en ese tiempo de fiesta pues ya, cuando está ya en esa fecha.

${ }^{13}$ Procedimiento que en lingüística se conoce como alternancia de código o code switching. 
Subalternidad y contrahegemonía en la narrativa testimonial kichwa de la sierra norte del Ecuador

Sintetizando todo lo dicho hasta aquí, el uso del discurso reportado directo es una herramienta narrativa útil para relatar un evento de la manera más real posible, sin dejar de cumplir los requisitos de una comunicación exitosa (Grice 1975: 43-58):

a). comunicar sólo aquella información de la que poseemos evidencia (máxima de calidad)

b). ser tan informativo como sea necesario para los propósitos del intercambio comunicativo (máxima de cantidad)

c). hacer que la información comunicada sea relevante para la interacción (máxima de relevancia)

d). evitar la oscuridad y la ambigüedad en la expresión y procurar ser claro y ordenado (máxima de manera)

Con base en lo anterior, precisamos en los siguientes términos la afirmación corriente de que el testimoniante denuncia la condición subalterna: el sujeto narrativo del testimonio denuncia la condición subalterna de su grupo de referencia, pero en calidad de voceador de éste, no se apropia directamente de los discursos individuales sino que los pone en boca de los propios individuos que sufren dicha condición, lo cual tiene el doble propósito de reforzar la denuncia y asignarla a un individuo de carne y hueso. Creemos pues que el narrador testimonial ejerce una verdadera labor periodística de compromiso político con su realidad social e informativo con su audiencia.

\section{La estetización del testimonio: modalidad, comparación y evaluación}

En la sección anterior subrayamos el compromiso de los narradores con la veracidad. Esto no significa que los testimoniantes se comprometan con determinados valores de verdad, sino simplemente que procuran ofrecer todos los elementos de juicio disponibles para que el receptor esté en condiciones de evaluar sus enunciados. La forma general en que se expresa este compromiso con la veracidad se conoce como 'modalidad', definida como la relación que establece el autor de un enunciado con dicho enunciado. La modalidad puede ser epistémica - si se refiere a los grados de probabilidad de un enunciado - o deóntica - si se refiere a la necesidad u obligación que establece un enunciado. Aparte de los mecanismos lingüísticos que tiene cada lengua para establecer la modalidad como marcar la fuente de un enunciado - todas las lenguas tienen una forma gramatical de modalidad que se basa en distinguir entre enunciados declarativos, enunciados interrogativos y enunciados imperativos. A partir de esta división, podemos caracterizar cualquier tipo de género discursivo. En el caso del testimonio, el análisis establece un predominio absoluto de enunciados declarativos. Al ser un género narrativo, faltan por completo en el testimonio los enunciados imperativos, salvo en los casos en que aparecen como parte del relato; también faltan los enunciados interrogativos, pues el narrador no pretende establecer un diálogo con su interlocutor sino más bien darle a conocer una realidad desde su perspectiva.

Como señalamos anteriormente, aún cuando conserva su compromiso con la veracidad, el testimonio no pretende erigirse como discurso políticamente neutro. Todo lo contrario, en su denuncia y su posición interpelante del poder establecido radica su eficacia simbólica de representación de lo subalterno. Por esta razón, también encontramos en él un posicionamiento claro del sujeto narrador a través de dos mecanismos - menos frecuentes que los analizados hasta ahora pero no por ello menos eficaces: la comparación figurada y la evaluación. Entendemos la primera como el trazado explícito de semejanzas entre objetos extra-textuales que va de lo real a lo figurado; y la segunda como la asignación de un valor a un objeto extra-textual según parámetros de diferente tipo. Estos parámetros no se asumen como universales sino se basan en la cosmovisión que el narrador comparte con su(s) grupo(s) de referencia. Aunque está fuera de nuestro objetivo un análisis completo de estos mecanismos que contribuyen al posicionamiento epistémico del testimoniante, presentamos a continuación algunos casos que iluminan el uso de la comparación y la evaluación en el testimonio.

Para empezar debemos aclarar que no se encontró en el corpus un solo caso de comparación figurada implícita de tipo metafórico ( $\mathrm{X}=\mathrm{Y}$, $\mathrm{x}$ es $\mathrm{y})$. Todas las comparaciones figuradas son explícitas (X Y, $x$ como y) y se refieren sin excepción a objetos del entorno físico o social del testimoniante en el pasado o el presente. 
El carácter objetivo de las comparaciones concuerda con lo dicho antes sobre la declaratividad como modo gramatical propio del testimonio. Tomemos como ejemplo la comparación que establece un testimoniante al describir un toro de las corridas de Zuleta (23) y el tipo de pan que la hacienda entregaba en las fiestas de uyanzas (24):

23. atribik turirukuna tiyashpaka turiachun, pukllachun, fiestata yalingapak, intunsis puka uchuka, fiña wakra nishka, famadu wakra karka, piru yapudor wakra carca. [había toreros intrépidos que toreaban para celebrar las fiestas, por aquél entonces corría 'ají rojo', así le decían a un toro bravo, un toro famoso pero que era de labranza]

24. kaymi karak karka, jatun tanda, ñukanchik kunan kay matrimuniukunapi miza tanda ninchi, burru tanda ninchi, chay tandapish yali kasi chay jatun lavakarashina, chashna purti tandatami rurashpa karak karka. [esto sabían dar, pan grande, el pan que decimos de mesa que ahora hay en las bodas, que decimos 'pan de burro', más grande que ese pan era, como esa lavacara grande, de ese porte hacían el pan para dar]

El primer ejemplo contiene una comparación figurada entre el toro y el ají. Aunque el primero de los dos elementos no pertenece propiamente a la fauna andina - como pertenecería un camélido - es sujeto de comparación con un objeto que sí es endémico de la flora regional. La comparación es posible por las características asignadas al ají en el mundo andino y al color rojo como significante de dichas características: fiereza y dureza. Leída en el contexto del relato, la comparación adquiere mayor significado, cuando se asocia el color rojo del ají a la sangre derramada en las corridas a causa del animal. Nótese que la comparación no es producto del narrador sino una asociación en el imaginario de las comunidades que entra en el discurso del testimonio y muestra al hablante como usuario de un código cultural compartido. Esto se observa mejor en el segundo ejemplo, donde la comparación es un producto narrativo propio, basado en una práctica social que el hablante comparte con los demás miembros de su grupo de referencia. En este caso el pan que regalaba la antigua hacienda se compara con el pan de la mesa ceremonial en las bodas indígenas locales que se celebran hoy en día. En ambas comparaciones resulta interesante que los términos de la comparación, si bien se refieren a objetos propios del medio físico y cultural del testimoniante, llevan nombres que son préstamos castellanos: miza ‘mesa' y burru ‘burro'. Es posible que esto se deba, al menos en algunos casos, a que los objetos referidos forman parte de prácticas que incorporan aspectos que no son nativos. Admitimos que ésta es sólo una posibilidad y es necesario un estudio más profundo de las relaciones semánticas en los préstamos castellanos del kichwa local para poder emitir un juicio al respecto.

Para ilustrar el uso de las evaluaciones me enfocaré en dos parámetros recurrentes en los testimonios, que tienen que ver con la dureza del trabajo en la hacienda y la aspereza de carácter de administradores y mayordomos. En el primer caso el trabajo para la hacienda - sea éste desempeñado por un gañán, un yanapero o una concierta - se evalúa con el atributivo llakishka 'doloroso' o con sus equivalentes castellanos sufridor y jodido. Los siguientes ejemplos en kichwa y castellano muestran este tipo de evaluación:

25. ñuka papasu rishpaka, shamuichiyari yakuta aparicta aidawanguichi, ñuka warmillaka na abanzanka nishpa hashtaka tiyan, ñuka mamitaka, chay tiympupash warmi trabaju sufridur canka [cuando iba mi papacito, porque le hacía venir, ayudaba llevando agua diciendo 'mi mujer sola no avanza', era demasiado para mi mamacita, en ese tiempo el trabajo de la mujer sí que era sufridor]

26. yo también andaba en trilla hasta terminar todas las parvas de trigo o cebada, este trabajo cuando es al menos vicia o lenteja, necesita un urconcito para poder meter sin peligro al cilindro, sino pues solo con la mano no más pues es mucho peligro, es trabajo jodido, se ensucia a veces los granos también se brincan la cara, a los ojos

El primer relato es un caso de discurso reportativo directo mientras el segundo es un relato vivencial del hablante. Ambos 
Subalternidad y contrahegemonía en la narrativa testimonial kichwa de la sierra norte del Ecuador

comparten sin embargo la misma visión, que se trasluce por el modo semejante en que evalúan el trabajo en la hacienda. Más aún, la evaluación que hace la concierta en (25) es enfática y gira en torno al género porque no se refiere al trabajo en general sino específicamente al trabajo de las mujeres, comparándolo tácitamente con el trabajo ligero que cumplen hoy en día.

Cuando la evaluación tiene que ver con las personas que imponen la dureza del trabajo, los testimonios concuerdan en asignar una cualidad específica a dichas personas: la cólera. Así describe el testimoniante a uno de ellos:

27. chayka siñura Nicolasa Serrano nishka, chay señoraka mayordomoka, ninan fiera ya ninan fiera, dénme sacando agua, no han dado sacando agua nishpaca, ñuka mamitaca llakishka yakukuta, baldita satishpaka, Chualpamba talishpa, animalta jilajuna nin [esa señora Nicolasa Serrano, esa señora era mayordoma, era muy colérica, muy colérica, decía 'déme sacando agua, no ha dado sacando agua' y mi mamita dizque sufría sacando agua con balde para regar en Chualpamba y dar a los animales].

El hablante evalúa el carácter de la mayordoma no sólo asignándole un calificativo (fiera) sino utilizando el reportativo directo. Sin embargo, reconoce que su fuente de información no es personal y usa por lo tanto el reportativo indirecto.

Por otro lado, llama la atención que el mismo atributivo (fiero) sea utilizado a menudo para evaluar la vida en la hacienda, tendiendo así un puente entre ambos tipos de evaluaciones - del trabajo y de la gente. El siguiente pasaje contiene el término 'fiero', utilizado como un adverbio que caracteriza la acción de ‘vivir'.

28. shinami, chay tiympuka fierotami kawsashkanchi, martista llucshishkanchi, miyrkulistapash Ilucshishkanchi, wakin animal charikka, asta lunis a viyrnismari purina. [así era, en ese tiempo vivíamos sufriendo, salíamos el martes, salíamos el miércoles, algunos tenían animales, esos salían de lunes a viernes]
Al no existir una equivalencia exacta en castellano para el adverbio fierotami, lo hemos traducido como el gerundio del verbo 'sufrir'. Un análisis de los componentes semánticos de ambos elementos sugiere efectivamente que 'fiero' y 'sufridor' - pero también el kichwa fiña ‘fiero, bravo' en (23) - tienen mucho en comun. Asimismo, el análisis de otras evaluaciones arroja una forma adverbial que concuerda con la semantica de los atributivos anteriores: nos referimos al vocablo lashtima, del castellano 'lástima', en el sentido de 'doloroso' o ‘dolorosamente'. En resumen, atributivos que comparten el mismo campo semántico de fiña o fiero se utilizan para caracterizar a los miembros del grupo hegemónico mientras que aquellos que comparten el campo semántico de sufridur y lashtima marcan la condición subalterna de las comunidades en el discurso.

El precedente no es más que un análisis preliminar y de alcance limitado sobre las concepciones del poder y lo subalterno y su estetización en el discurso. Como señalamos al iniciar esta sección, es necesario un estudio más profundo de las comparaciones figuradas y las evaluaciones con base al análisis del lenguaje que utilizan los narradores a la hora de entregar sus testimonios.

Lo dicho hasta aquí nos permite ofrecer algunas conclusiones preliminares sobre cómo se construyen las identidades en el testimonio y cómo éste se caracteriza por un conjunto de rasgos lingüísticos que lo distinguen como un género mediado por prácticas sociales pasadas que siguen siendo el marco de referencia para la estructura de un poder local que sólo ha pasado de manos.

\section{Discusión: identidades construidas y entidades referidas}

En las secciones anteriores demostramos con datos empíricos varias de las afirmaciones corrientes sobre algunas características discursivas del testimonio. Para ello encuadramos la discusión en el marco del Análisis Crítico del Discurso, por considerarlo una disciplina que vincula de manera más equilibrada el análisis del lenguaje con el 
problema del poder y la representación. En esta sección ofrecemos una visión de conjunto del testimonio como configuración discursiva caracterizada por las estrategias etnopragmáticas que presentamos en secciones anteriores.

El objetivo de este estudio fue comprender el papel que cumplen en la construcción discursiva de la identidad las estrategias etnopragmáticas relativas al uso de los pronombres, el discurso reportado directo, las comparaciones figuradas y las evaluaciones. Con este objetivo empezamos por identificar en el discurso del testimonio dos grandes áreas de representación, una relacionada con los procesos o actividades públicas, otra con las experiencias grupales e individuales. A partir de esta división encontramos que el primer tipo de representación está caracterizado por una anulación de la agentividad a través de la elisión pronominal y el uso de formas verbales impersonales. Contrasta la visión de la hacienda como un agente unitario dotado de organicidad, al que se asigna siempre una forma verbal definida aun cuando aparezca implícito. En el segundo tipo de representación - las experiencias - encontramos una configuración lingüística relativamente difusa, donde el uso del pronombre singular de primera persona que designa al sujeto narrador se entremezcla de diversas formas con el plural de la misma persona. Sin embargo, descubrimos que dicha mezcla no es arbitraria y obedece a un proceso de construcción de la identidad del sujeto narrativo a partir de su pertenencia a diferentes colectivos sociales. Concordantemente, identificamos una mayor frecuencia relativa de uso del 'nosotros' con respecto al 'yo' y aislamos los distintos referentes del primero en cuanto a lo genérico, étnico y económico. Dentro de lo genérico hallamos que el sujeto narrativo se construye sobre todo con respecto a la familia y al grupo de edad. En lo étnico el punto de referencia es el colectivo social que vive una condición subalterna y que se distingue cultural y lingüísticamente del mundo mestizo. En lo étnico se observó también la identificación del hablante como miembro de un subconjunto (cayambe) del primer colectivo, distinto de otro subconjunto (otavaleño) del mismo colectivo. Por fin, en lo económico, encontramos que el sujeto narrativo construye su identidad a partir de su pertenencia o no a la hacienda.
El proceso de identificación a partir de colectivos se materializa en el discurso a través de dos mecanismos lingüísticos. El uno es la alternancia de formas pronominales y verbales correspondientes a manera de serie ordenada. La forma de esta alternancia se puede representar con la siguiente notación:

a) Alternancia: ... 1P, 1S, $1 \mathrm{P}, 1 \mathrm{~S} \ldots(3 \mathrm{~S}),(3 \mathrm{P}) \ldots \mathrm{1S}, 1 \mathrm{P}, 1 \mathrm{~S}, 1 \mathrm{P}, \ldots$

Donde $1 \mathrm{P}$ y $1 \mathrm{~S}$ corresponden, respectivamente, a cualquier referente colectivo o individual (incluido el hablante), pudiendo introducirse en medio referentes colectivos o individuales de tercera persona que marcan la diferencia con los primeros y sirven para su identificación. Mientras que en los testimonios analizados el requisito único para la construcción identitaria del sujeto narrativo es establecer su pertenencia a un colectivo social, esta construcción puede reforzarse con la presencia de otros colectivos (3Ps) a los que no pertenece el testimoniante.

El segundo mecanismo a través del cual el sujeto se identifica con entidades de referencia es la sinécdoque, tropo del lenguaje que se basa en relaciones de inclusión y exclusión entre elementos y que puede describirse con la siguiente notación:

b) Inclusión: $1 \mathrm{~S} \subset 1 \mathrm{P}, 1 \mathrm{P} \subset 1 \mathrm{P}, 3 \mathrm{~S} \subset 3 \mathrm{P}, 1 \mathrm{~S} \subset 3 \mathrm{P}$

c) Exclusión: $1 \mathrm{~S} \not \subset 1 \mathrm{P}, 1 \mathrm{P} \not \subset 1 \mathrm{P}, 3 \mathrm{~S} \not \subset 3 \mathrm{P}, 1 \mathrm{~S} \not \subset 3 \mathrm{P}$

Primero, $1 \mathrm{~S} \subset 1 \mathrm{P}$ significa que el sujeto narrador pertenece o está incluido en un 'nosotros' con referente específico. Por su parte, $1 \mathrm{P} \subset 1 \mathrm{P}$ indica que un colectivo al que pertenece el narrador es subconjunto de otro más grande al que también pertenece el narrador. Por fin, las exclusiơnes $1 \mathrm{~S} \not 1 \mathrm{P}$ y $1 \mathrm{P} \not 1 \mathrm{P}$ indican la no inclusión del elemento izquierdo de la relación en el elemento derecho.

Otro mecanismo lingüístico que sirve para marcar identidades y posicionar al sujeto narrador frente al discurso es la reproducción de palabras atribuidas a terceros (discurso reportado directo/indirecto), con el fin de actuar el relato y comprometerse con la veracidad de 
la enunciación. El análisis encontró que este procedimiento no sólo es frecuente en los testimonios sino que además cumple funciones explicativas y dialógicas, produciendo como efecto colateral el sentido de intertextualidad propio del testimonio.

Más todavía, este mecanismo resulta consustancial al género testimonial porque los hablantes lo usan tanto en kichwa como en castellano e incluso introducen frases de una lengua en la otra (alternancia de códigos).

De esta manera podemos encontrar no sólo secuencias del tipo K_C_K, donde frases en castellano se insertan en una matriz kichwa, sino también del tipo C_K_C, donde frases en kichwa se insertan en una matriz castellana. Este mecanismo reproduce la polifonía del texto y sigue al mismo tiempo los criterios de un buen evento comunicativo, porque toda información que consigna indica su fuente.

Finalmente, un estudio preliminar de la comparación figurada y la evaluación nos mostró cómo el testimonio crea una estética particular asociada con el ejercicio del poder y la condición subalterna de los sujetos. Encontramos que al trazar semejanzas entre los enunciados el narrador del testimonio vincula objetos de su medio físico o sociocultural del pasado con objetos de su medio físico o sociocultural del presente.

Asimismo, como antiguo trabajador de la hacienda evalúa su actividad laboral y su relación con las personas encargadas de supervisarla. Para ello utiliza términos que indican la explotación de la mano de obra y la violencia verbal de los agentes del poder. Tomados en conjunto, estos términos configuran una estética de las relaciones sociales que se asienta en el imaginario de las comunidades y se reproduce en su discurso.
Cuadro 2. Relaciones semánticas entre elementos del espacio hacendatario.

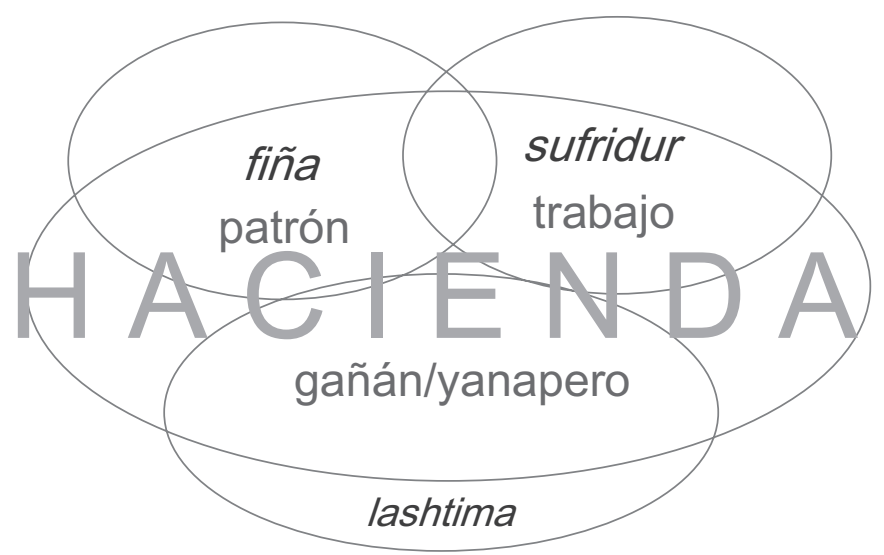

\section{Conclusiones}

Si bien la presente investigación estuvo delimitada por la naturaleza del corpus sometido a análisis, se propuso sentar las bases para ejercicios similares en narrativas testimoniales, como una nueva forma de rescribir la historia de los grupos subalternos, en particular, de las comunidades indígenas de nuestro país, centenariamente sometidas al dominio hegemónico de la sociedad hispanohablante blanco-mestiza pero al mismo tiempo conscientes de su iniciativa histórica.

Los testimonios recogidos en las comunidades kichwas de la cuenca del lago San Pablo se enmarcan en una práctica narrativa a través de la cual el individuo se socializa como miembro de una comunidad con rasgos culturales, sociales y lingüísticos propios, anclada en un pasado reciente en que la hacienda determinó su acceso a los recursos naturales y su reproducción. Desde esta perspectiva, los testimoniantes rescatan para las generaciones presentes la memoria de una condición subalterna del pasado que continúa configurando su condición aún subalterna en el presente. 
La práctica del testimonio emerge en las comunidades como una necesidad semiótica de entender el presente a través del pasado y se constituye así en una práctica social que crea la realidad (Fowler 1985: 62). A diferencia de narrativas hegemónicas que cumplen similar función, el testimonio desafía el control discursivo de los grupos de poder, tejiendo a través de su lenguaje un orden del discurso alternativo, con sus propias reglas de enunciación, sus voces y su estética. Mas este ejercicio de representación no busca la hegemonía ni el control de la opinión. Los mecanismos dialógicos y epistémicos del discurso demuestran su verdadera orientación: el ejercicio democrático de la palabra y el compromiso con la veracidad de lo enunciado. Así, los testimonios que hemos analizado buscan la denuncia en lugar de la hegemonía, favorecen el diálogo en lugar del monólogo, persiguen la veracidad en lugar de ‘la' verdad, y construyen su versión de los hechos sin asumirla como la única posible.

Al evaluar la utilidad del análisis del discurso para la historia, Struever (1985: 250) sostiene que aquél es doblemente heurístico porque funciona como crítica de las fuentes y autocrítica de la práctica historiográfica. De igual manera, creemos que una investigación que aplique las herramientas del Análisis Crítico del Discurso a géneros orales como el testimonio nos abrirá la puerta a nuevas historias pero al mismo tiempo nos enseñará a contar mejor nuestro pasado.

\section{Reconocimientos}

El análisis del corpus reunido para este artículo se realizó gracias a una beca de investigación de la Universidad Andina Simón Bolívar en el año 2009. Agradezco a los dos revisores anónimos por sus comentarios y sugerencias.

\section{Referencias}

Beverley, J. (1987). Del Lazarillo al Sandinismo. Minnesota: Ideología y Literatura.
Beverley, L. (1999). Subalternity and Representation. Arguments in Cultural Theory. Durham: Duke University Press.

Bourdieu, P. (1997). Razones Prácticas: sobre la teoría de la acción. Barcelona: Editorial Anagrama.

Brown, R. \& Gilman A. (1960). The pronouns of power and solidarity. En T. A. Sebeok (Ed.), Style in Language (pp. 253-76). Cambridge: MIT Press.

Fairclough, N. (1995). Critical Discourse Analysis. The Critical Study of Language. Reino Unido: Longman.

Fairclough, N. (2008). Analysing Discourse. Textual Analysis for Social Research. Oxon: Routledge.

Fairclough, N. \& Wodak, R. (1997). Critical discourse analysis.

En T. A. van Dijk (Ed.), Discourse Studies. A Multidisciplinary Introduction, Vol. 2. Discourse as Social Interaction (pp. 25884). London: Sage.

Foucault, M. (1969). L’archéologie du savoir. París: Gallimard.

Foucault, M. (1992). El orden del discurso. Buenos Aires: Tusquet Editores.

Fowler, R. (1985). Power. En T. van Dijk (Ed.), Handbook of Discourse Analysis 1: Disciplines of Discourse. (pp. 61-82). Londres: Academic Press.

Gómez Rendón, J (2001). La voz del subalterno a través del testimonio: una fuente para el estudio de las relaciones de poder en las fiestas de la parroquia San Pablo del Lago. Tesis de Maestría. Universidad Andina Simón Bolívar, Quito: UASB.

Gómez Rendón, J. (2006). Interpersonal Aspects of Evidentiality in Ecuadorian Quechua. ACLC Working Papers 1.

Gómez Rendón, J. (2008). Mestizaje lingüístico en los Andes. Génesis y Estructura de una Lengua Mixta. Quito: Editorial Abya Yala.

Grice, H. P. (1975). Logic and conversation. En P. Cole \& J. Morgan (Eds.), Syntax and Semantics 3: Speech Acts (pp. 41-58). Nueva York: Academic Press. 
Subalternidad y contrahegemonía en la narrativa testimonial kichwa de la sierra norte del Ecuador

Haboud, M. (1998). Quichua y Castellano en los Andes Ecuatorianos: los efectos de un contacto prolongado. Quito: Ediciones Abya Yala.

Muysken, P. (1985). Contactos entre Quichua y Castellano en el Ecuador. En S. Moreno Yánez (Ed.), Memorias sobre el Primer Simposio Europeo sobre Antropología del Ecuador (pp. 377472). Quito: Editorial Abya Yala.

Polanyi, L. (2001). The Linguistic Structure of Discourse. En D. Schiffrin, D. Tannen \& H. E. Hamilton (Eds.), The Handbook of Discourse Analysis (pp. 265-281). Londres: Blackwell Publishing.

Spivak, G. (1988). Can the Subaltern speak? En C. Nelson \& L. Gossberg (Eds.), Marxism and the interpretation of culture (pp. 24-28). Londres: Macmillan.

Struever, N. (1985). Historical Discourse. En T. van Dijk (Ed.), Handbook of Discourse Analysis 1: Disciplines of Discourse (pp. 249-271). Londres: Academic Press.

Van Dijk, T. (1993). Principles of Critical Discourse Analysis. Discourse and Society 4(2), 249-283.

Van Dijk, T. (2001). Critical Discourse Analysis. En D. Schiffrin, D. Tannen \& H. E. Hamilton (Eds.), The Handbook of Discourse Analysis (pp. 352-371). Londres: Blackwell Publishing.

Wodak, R. (2001). What is CDA about? - a Summary of its History, Important Concepts and Its Developments. En R. Wodak \& M. Meyer (Eds.), The Handbook of Discourse Analysis (pp. 1-13). Londres: Sage Publications. 